\title{
Parliamentary News \\ Progress Report on the Mental Health (Amendment) Bill
}

The Bill has passed through the House of Lords and the Committee Stage of the House of Commons. The latter was by means of the new Special Standing Committee procedure which afforded an opportunity for giving written and oral evidence, submission of amendments for consideration and lobbying by correspondence and personal discussion with MPs and government officials. Written and oral evidence was given (and published in Hansard) from, inter alia, the Royal College of Psychiatrists and Special Hospital psychiatrists. The President, Professor K. Rawnsley, and Professor R. Bluglass gave oral evidence for the College and submitted evidence in writing. The Special Standing Committee visited Broadmoor Hospital and also held an informal 'teach in' on consent to treatment.

The Bill now passes to Report Stage and Third Reading in the Commons during the current Parliamentary session and then returns to the House of Lords for ratification before receiving the Royal Assent. The following is a summary of the major amendments to the Mental Health Act which have been made.

\section{'Mental impairment'}

There is to be a change in terminology from mental subnormality, not to mental handicap as originally proposed by the Government and welcomed by the College, but to 'mental impairment' and 'severe mental impairment', and the definition has been changed to: 'a state of arrested or incomplete development of mind which includes significant impairment of intelligence and social functioning and is associated with abnormally aggressive or seriously irresponsible conduct.'

\section{Psychopathic disorder}

The age limits for detention of non-offenders has been abolished. Instead, at admission and renewal of detention there shall be (and this applies also to mental impairment) a criterion that treatment is likely to alleviate or prevent a deterioration' of the patient's condition. At present patients cannot be detained by reason only of promiscuity or other immoral conduct and this will now have added to it 'sexual deviancy or dependence on alcohol or drugs'.

\section{Admission for observation}

Section 25 will now be 'admission for assessment', for 28 days as before, and it will be made clear that assessment includes treatment. The Opposition were unsuccessful in an attempt to include crisis intervention centres along with hospitals as places for detention. Patients on a Section 25 Order will have the right to apply to a Mental Health Review Tribunal (MHRT) within 14 days of admission, but the chairman of the Tribunal will have the right to make flexible arrangements for the hearing.

\section{'Holding power' for nurses}

Registered mental nurses (RMN) and RMN(S)s (subnormality) will have the power to detain an informal patient in hospital for 6 hours to enable a doctor to be found to approve a Section 30 Order. It is possible at the Report Stage that the Opposition will seek to have that period reduced to three hours.

\section{'Approved social workers'}

Mental welfare officers are to be replaced by approved social workers who will have undergone approved training and have specified qualifications.

\section{Definition of nearest relative}

The Opposition were successful in having included in the list of relatives of patients, cohabitees who have lived with the patient for five years. The cohabitee may be of the same sex as the patient.

\section{Duration of detention}

Detention under Sections 26 and 60 will now last for six months and have to be renewed after a further six months, and thereafter annually. Consequently, patients will have twice as many opportunities for appeals to MHRTs. The criteria for renewal of detention includes 'alleviation or prevention of deterioration' for psychopathic disorder and mental subnormality. As an alternative, for mental illness or severe mental impairment, the criteria can be that the patient, if discharged, would be 'unlikely to be able to care for himself or guard himself against serious exploitation'.

\section{Hospital orders}

The Opposition are likely to attempt again at Report Stage to have passed an amendment whereby courts will be empowered to direct Regional Health Authorities to provide a bed for an offender-patient. The wording for Restriction Orders is to be changed to make it clear that the purpose is to protect the public from serious harm. Doctors will have to send annual reports on restricted patients to the Home Secretary.

\section{Mental Health Review Tribunals}

MHRTs will have the power to order the discharge of restricted patients if they consider the patient not to be dangerous or no longer suffering from mental disorder. Tribunals for restricted patients will be enhanced so that the chairman will be a judge. There will be automatic Tribunals for patients who have not asked for a hearing in any three- 
year period. Tribunals will be able to order delayed discharge and patients will be entitled to be provided with legal 'assistance by way of representation' (ABWOR).

\section{After-care}

Against the Government's wishes an amendment was passed placing a duty on Health Authorities and Social Services to provide after-care for detained patients when they leave hospital.

\section{Remands to hospital and interim hospital orders}

Courts will have the power to remand someone charged with an imprisonable offence to hospital (including a Special Hospital) either for treatment or for assessment and reports. The remands will be for a month at a time, up to a maximum of three months. Remands for treatment will not apply to those charged with murder. Interim hospital orders can be made following conviction to see whether this is the most appropriate disposal: they can last for up to six months.

\section{Transferred prisoners}

Prisoners transferred to hospital on a Section 72 Order will have their legal status changed to a 'notional Section 60 ' at the time of their 'earliest date of release' (had they remained in prison and earned a full one-third remission) instead of at the expiry of their sentence as at present.

\section{Voting rights}

The Government was defeated by an Opposition amendment giving voting rights to all mental hospital patients, including detained patients.

\section{Section 141}

Section 141, which seeks to protect staff for acts done in pursuance of the Act, has been amended so that civil proceedings will require leave of the High Court and criminal proceedings the consent of the Director of Public Prosecutions (DPP). The terms 'substantial ground' and 'bad faith' have been removed, and the Section no longer affords protection to the Secretary of State or Health Authorities.

\section{Correspondence of patients}

Mail from a detained patient may be withheld if the recipient has so requested, or if it is from a Special Hospital patient or if it is thought likely to cause distress to the recipient or cause danger. Mail to a patient can be withheld in the interests of the safety of the patient or to protect others. No mail can be stopped to or from those on an enlarged 'protected' list and rights of representation and appeal are included.

\section{Mental Health Act Commission}

Probably the most important provision in the Bill is that establishing a new multidisciplinary, independent body to exercise general protective functions in respect of detained patients. The Commission will regularly visit all psychiatric hospitals, look at detention and treatment records, interview patients, examine complaints, publish an annual report, and appoint doctors to give opinions on consent to treatment. Its scope has now been widened to include some responsibilities for informal patients.

\section{Code of Practice}

The Government, after consultation, will prepare a Code of Practice for the guidance of psychiatrists and other staff on admissions and treatments of detained patients. The Code will specify forms of treatment advising consent and a second opinion in addition to those treatments specified in Regulations.

\section{Consent to treatment}

The most controversial part of the Bill was finally passed as a compromise package. The new provisions do not apply to patients on short-term detention Orders or on remand for reports, but do include Section 26 patients on leave of absence. Treatments requiring consent and/or a second opinion do not apply to urgent treatments which are lifesaving, or immediately necessary to prevent violence, a serious deterioration in the patient's condition or to alleviate serious suffering. Consent and second opinions may refer to a plan of treatment rather than individual courses.

One clause refers to treatment requiring the patient's consent (capable of understanding the nature, purpose and likely effects of the treatment) and a mandatory concurring second opinion. The latter will be provided in writing by a doctor appointed by the Mental Health Act Commission and two others who are not doctors who will certify as to the patient's competence to consent. The doctor alone will give an opinion on the validity of the proposed treatment. The treatments here will include psychosurgery and such other treatments as are specified in Regulations.

Another clause concerns treatments requiring consent or a second opinion and includes medication, ECT and such other forms of treatment and diagnostic procedures as may be specified in Regulations. For these treatments, if a patient does not consent or is incapable of consenting, a second medical opinion will also be necessary and the independent doctor will be required to consult a nurse and one other professional person concerned with the patient's treatment. This does not, however, apply to medicines (other than those in Regulations) given in the first three months following detention. Medical treatment may be given upon a doctor's own decision without reference to the Commission providing that the medicine is not in the limited category to which consent and second opinion must be obtained. To continue treatment beyond three months, consent or a second opinion must be obtained. It has not yet been decided what happens after three months. One possibility is that of notification to the Commission of lack of or inability to consent, at each renewal of detention, leaving it to the Commission to decide whether or not to seek a second opinion.

Discussions are continuing between the College and the Department concerning outstanding matters deferred from the Committee Stage to the Report Stage, and these will be reported on in a later issue.
JOHN R. HAMILTON 